\title{
A CASE OF DIABETIC RETINITIS
}

BY

\author{
A. B. ZORAB
}

SOUTHAM PTON

THE interest of this case lay entirely in the picture presented by the fundus oculi.

C. $P$. A., aged 22 years, a young soldier, was admitted to the Royal Hampshire County Hospital, Winchester, on November 19, 1917 , complaining of thirst and of passing large quantities of urine. The condition had been noticed for a month. He was found to have sugar in his urine. He was in the wards between November 19,1917 , and January 29,1918 . He was put on a carbohydratefree diet and treated with sodii bicarb. ; tr. camph. co. and codia at intervals. During his stay his urine was measured and tested daily. The quantity varied from 100 ozs. to 210 ozs. in the 24 hours, the sp. gr. varied between 130 and 140, and the sugar from 13 to 40 grs. per ounce. A blood count gave :-

$$
\begin{array}{llllr}
\text { Reds } & \ldots & \ldots & \ldots & 3,000,000 \\
\text { Whites } \ldots & \ldots & \ldots & 15,000 \\
\text { Polymorphs } & \ldots & \ldots & 85 \text { per cent. } \\
\text { Lymphocytes } & \ldots & \ldots & 15 \text { per cent. }
\end{array}
$$

As far as his diabetes was concerned, when he left the hospital he was no better and no worse.

I was first asked to see him on November 28, 1917, as he had complained of slight mistiness of vision on reading. His vision was $6 / 6$ in each eye, but in order to examine him fully I ordered that his pupils were to be dilated for my next visit the following week.

I quote the notes:-

December 5, 1917. Under homatropine. V. with $+2.5 \mathrm{D}$. sph. $=6 / 6$ each eye. Fundus very suspicious of retinitis-shiny white exudate. Ord. $+2 \cdot 0 \mathrm{D}$. sph. I want to see this patient every week.

December 12, 1917. The retinae are oedematous and the vessels are coated with the usual whitish exudate. V. $6 / 9$ to $6 / 12$.

December 19, 1917. All the retinal vessels-even to the terminal twigs-are coated with a glistening white exudate filling up the sulcus between vessel and retina. The retinal condition is very unsatisfactory: oedematous but no haemorrhages. Vision is $6 / 6$ each eye.

January 9, 1918. The retina itself has lost most of its oedema, but the discs are blurred. All the retinal vessels are white as though they contained chyle and not blood. They can be seen in their finest filaments which anastomose at the periphery. $V=6 / 9$ each eye. 
January 14, 1918. The arteries and veins are still white and I have now been able to confirm the anastomoses of the smaller arteries in at least three positions in each eye-right at the periphery. The whiteness is less marked than it was last week.

January 23, 1918. The arteries and veins have lost their white appearance and consequently cannot be traced outwards very far. V.c $+1 \cdot 5 \mathrm{sph} .=6 / 9$ full each eye. ${ }^{*}$

It is difficult to convey in words the very striking picture presented by the fundus in this case. The general reflex was the usual well-known crimson red, slightly blurred perhaps by the oedema of

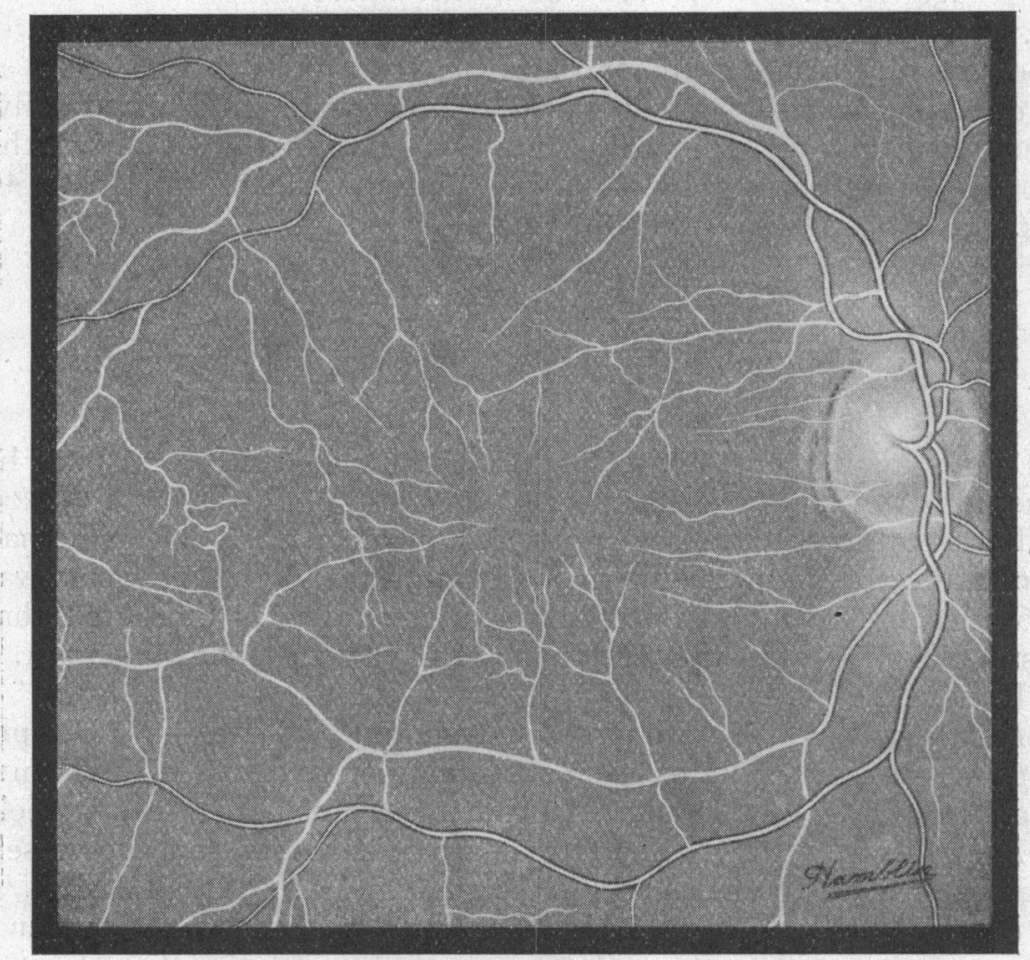

the retina. Against this background the vessels showed up in a startling fashion silvery white, bright and distinct, even the smallest twigs could be seen quite easily by the direct method-the hypermetropia making it all the easier to focus on them. The pupils dilated very widely and the extreme periphery of the fundus could be seen. I could follow an artery from one of the main branches

* The notes and commentary were written in 1918. 
of the central retinal, then to a smaller branch and so on till it broke up into a veritable net-work and could trace back a vein from this net-work to the main veins. In three separate parts of the fundus of each eye, I could see with absolute distinctness, beyond any possibility of mistake, an anastomosis between two small arteries. There were two such anastomoses between branches of the inferior and temporal retinal arteries and one such anastomosis between branches of the inferior and nasal retinal arteries.

I could find no such anastomosis in the upper half of the fundus in either eye. From first to last the media remained absolutely clear and I never could detect the smallest trace of a retinal haemorrhage at any period.

On referring to Fuchs' Text Book of Ophthalmology (fifth . edition, pp. 580-581), I found the following:-“Very rarely in young diabetics, especially when nearing death, retinal lipaemia is found, i.e., a condition in which on account of the large amount of fat in the blood, the retinal vessels appear reddish white or pure white." This statement is by Duane.

Such a condition was not found in the case described above. The blood examination failed to reveal any marked divergence from the normal, and its colour, when drawn from a pricked finger, was quite satisfactory. Further, the filling in of the sulcus between the walls of the larger vessels and the retina showed the presence of an exudative coating.

\section{ANNOTATION}

\section{Blindness in Trinidad and Tobago}

A valuable attempt, admittedly incomplete, has been made by Mr. Métevier towards the correct estimation and prophylaxis of blindness in Trinidad and Tobago. As a foundation for further work in these islands the report, which will be laid before the Legislative Council, is admirable, and some interesting facts are recorded in it. In this colony the question as to whether a person is blind or not has up to the present been largely decided by the Committee of the Institute for the Blind. The granting of Poor Relief last year has brought the condition of economic blindness in some cases of unemployment and indigence before the Inspector for Poor Relief. No further state action for dealing specifically with the blind has been taken; but, acting on the suggestion of Mr. and Mrs. Holt Mather, of New York, the Committee of the Institute of the Blind has had under consideration the preparation of a census of the blind in this colony. Mr. Métevier has examined the cases in the various institutions, and has added details of 53 patients seen in private between January 1, 1931 and April 30, 1932. 